\title{
The Uncertainty Assessment of Threonine Determination in Ginseng and Its Immune Activity
}

\author{
Jane yuxia Qin, Yan Chen, Dianshuai Gao and Ye Xiong ${ }^{*}$
}

Department of Neurobiology, Xuzhou Medical College, Jiangsu Province, 221994, China

\begin{abstract}
Ginseng is one of famous herbs, which has many medical functions, such as neuroprotective effects, and anticancer function, because ginseng contains many active substances, and threonine is one important ingredient. In this study, to establish a mathematical model of uncertainty assessment for Threonine content in Ginseng by the amino acid assay, the sources of uncertainty in the measurement process were completely concerned, the main sources of uncertainty were fully analyzed, and evaluated and calculated. The results showed, for $0.2083 \mathrm{~g}$ sample, the Threonine determination in Ginseng showed a good linear relationship. IN conclusion, this method developed in this study is suitable for the Uncertainty factors assessment of threonine measurement in Ginseng by amino acid assay. We also did animal test. To detect the immune activity of threonine in Ginseng, we detected the CD3+, CD19+ using FACS of mice after oral administration.
\end{abstract}

Keywords: Ginseng, threonine, Immune Activity, CD3+.

\section{INTRODUCTION}

Ginseng is a powerful herb which can improve immunity because they contain many medicine ingredient and nutritional ingredient. Threonine is one of the important nutritional ingredients. For a long time, the main method for determination of threonine in Ginseng is amino acid assay, and the experimental procedures have been very developed. But the results of the same sample showed a certain difference, which because those experiments are performed by different labs or different people in same lab. We analyzed the causes of the difference through the determination of threonine in Genseng, evaluated the sources of this uncertainty of these quantitative results, and found that the quantification of threonine showed in a certain confidence interval, which play the role of the correction on the measurement of threonine.

\section{MATERIALS AND METHODOLOGY}

Ginseng samples were farmed in Jilin Province, China, dried at $60^{\circ} \mathrm{C}$ after mashing using organizations broken machine, filtered with 60 mesh sieve after crushing by pulverizer, and then mixed, separately stored in bottle for detection.

Threonine reference substance were purchased from the Beijing Academy of Agricultural Sciences, $14.62 \mathrm{mg} / \mathrm{L}, 6.0$ $\mathrm{mol} / \mathrm{L}$ hydrochloric acid solution, guarantee reagent, Beijing Chemical industry; water is pure water, Hangzhou Wahaha

*Address correspondence to this author at Tongshan Road, Xuzhou, China. 221004; Tel: +8613814422945; Email: yuxiaemail@126.com
Group Co., Ltd. MCI Buffer L-8500-PH Kit for Mitsubishi Chemical Corporationg; Coloration liquid: R1, R2 is Japan, and by Wako Pure Chemical Industries Co., Ltd. All glassware and experimental apparatus are immersed by concentrated sulfuric acid, washed with deionized water.

$0.1 \mathrm{~g}$ of Ginseng powder were weighed by $0.1 \mathrm{mg}$ precision balance accurately and placed in the hydrolysis tube added $10.00 \mathrm{ml} 6.0 \mathrm{~mol} / \mathrm{L}$ hydrochloric acid, $\mathrm{N} 2$ flowed through for $1 \mathrm{~min}$, and covered with rubber plug. This hydrolysis tube was sealed after vacuumed by vacuum pump, placed in a $110^{\circ} \mathrm{C}$ thermostatic oven, hydrolyzed for $22 \mathrm{~h}$. When the hydrolysis ended, hydrolysis solution was filtered and transferred to a $50.00 \mathrm{ml}$ volumetric flask and add deionized water to a constant volume. $1.00 \mathrm{ml}$ filtrate was put into the beaker, and evaporated to dryness in a vacuum dryer, and then 1-2 $\mathrm{ml}$ of water was dissolved and then evaporated to dryness and repeated 2 times, and finally the residue was dissolved with $1.00 \mathrm{ml}$ of $0.02 \mathrm{~mol} / \mathrm{L}$ hydrochloric acid, filtered with $0.22 \mu \mathrm{m}$ polyethylene ether sulfone membrane filtration then for determination on the machine.

The temperature of the laboratory $(20 \pm 5){ }^{\circ} \mathrm{C}$; volumetric flask, straw and other glass container are according to the JJG196-2006 test procedures [1] Class B equipment standards; $0.1 \mathrm{mg}$ division balance was used according to JJG 1036-2008 Verification regulation for Electronic balance [2] requirements; testing instruments (Agilent1200) meet JJG705-2002 test requirements for Verification regulation of liquid chromatographs [3]. Methanol and other reagents meet the analytical criteria, water was Wahaha water.

Japan's Hitachi L-8800 amino acid analyzer; electronic analytical balance: $1712 \mathrm{mp} 8$ oven thermostat: DG 30/14-II. 
Table 1. The experimental design.

\begin{tabular}{|c|c|}
\hline Group & amount \\
\hline \hline control & 25 mice \\
\hline sinsenoside & 25 mice \\
\hline threonine & 25 mice \\
\hline Sinsenoside+threonine & 25 mice \\
\hline
\end{tabular}

Immunizing dose and approaches

Chromatographic column: Elipses XDB C18 $(4.6 \times 250$ $\mathrm{mm}, 4.6 \mu \mathrm{m})$; buffer: $\mathrm{PH} 1, \mathrm{PH} 2, \mathrm{PH} 3$ and $\mathrm{PH} 4, \mathrm{pH}$ 5; detection wavelength for reaction solution: R1, R2; $570 \mathrm{~nm}$ (visible light); buffer flow rate was $4.0 \mathrm{ml} / \mathrm{min}$, and the flow rate of reaction liquid was $4.0 \mathrm{ml} / \mathrm{min}$; column temperature: $57^{\circ} \mathrm{C}$; injection volume was $20 \mu \mathrm{l}$.

\section{Immunity Activity Detection on Animal}

100 Mice are divided into four groups as following (Table 1):

$5 \mathrm{mg}$ sinsenoside, threonine and Sinsenoside+threonine respectively was given to one $\mathrm{Bal} / \mathrm{c}$ mice by oral administration per day. 8 days later, half of each group mice for facs, and half of it were forlymphocyte transformation test.

Facs approaches:

1. The mice were killed and the put in $1 \%$ benzalkonium bromide for 3-5min.

2. Sterile gauze was prepared in sterile plates, and 2 $\mathrm{ml}$ PBS buffer was added into plates. The left lumbar region skin of mice was cut, spleen was taken out, put on gauze, and the spleen was minced into single cells.

3. The cells were transferred into centrifuge tubes, labeled, $1000 \mathrm{r} / \mathrm{min}$ for $10 \mathrm{~min}$, and discarded supernatant.

4. $500 \mu \mathrm{l}$ distilled water was added to precipitate, shaked gentlely, leaved there for $20 \mathrm{~s}$, removed red blood cell by cell disruption.

5. Appropriated amount PBS buffer was added into solution, in case the white cells break.

6. 2 min later, the supernatant was transferred into another tube, and labeled.

7. The cell solution was diluted into $1 \times 10^{6} / 100 \mu 1$ for facs.

$\mathrm{CD}^{+}{ }^{+} \mathrm{T}, \mathrm{CD}^{+} / \mathrm{CD}^{+}$and $\mathrm{CD} 19^{+}$was detected $\mu 1$ FITC labeled antibody to mice $\mathrm{CD}^{+}$put into each tubes. $\mathrm{PE}$ labeled antibody to mice $\mathrm{CD} 4^{+} \mathrm{T}, \mathrm{CD} 8^{+} \mathrm{T}$, and $\mathrm{CD} 19^{+}$, then $100 \mu 1$ cell supernatant solution $\left(10^{6} / \mathrm{ml}\right)$, incubated for $30 \mathrm{~min}$ at room temperature $\left(18^{\circ} \mathrm{C}-25^{\circ} \mathrm{C}\right)$, then detected by facs. $488 \mathrm{~nm}$ vave length for the detection of FITC, $533 \mathrm{~nm}$ vave length for the detection of PE, 10000 cells were detected, and analyzed by facs software.

\section{RESULTS AND DISCUSSION}

Preparation of standard curve: Take exactly $0.1,0.2$, $0.3, \quad 0.4,0.6 \mathrm{ml}$ reference substance Radix angelicae dahuricae with a $1 \mathrm{ml}$ single channel pipette. Get constant volume to $1 \mathrm{ml}$ and place in an automatic sampling bottle. According to above "chromatographic condition" to test peak area, using the least square method with the peak area $A$ and Radix angelicae dahuricae standard concentration $C$ $(\mathrm{mg} / \mathrm{ml})$ were for linear fit. The Radix angelicae dahuricae graticule is:

$A=0.2088+44.9649 C, r=0.9999$.

Determination of sample: Filtrate the sample solution with $0.22 \mu \mathrm{m}$ nylon membrane, according to 2 "chromatographic condition", determine on the machine. The peak area of the sample area was measured, and the results were shown in Table 2.

\section{Evaluation of Uncertainty}

Mathematical model

Mathematical calculation formula for Threonine content measurement:

$R=\frac{C_{\text {standard }} \times A_{\text {sample }} \times V_{\text {load }} \times V_{\text {volume }}}{A_{\text {standard }} \times m \times V_{\text {removal }} \times 10^{6}}$

where $\mathrm{R}$ is the threonine content in the sample, \%; Cstandard means reference sample concentration, $\mathrm{mg} / \mathrm{L} ; \mathrm{V}_{\text {volume }}$ is the final volume of the sample, $\mathrm{mL} ; A_{\text {sample }}$ means peak area of a sample $\mathrm{mAu} ; A_{\text {standard }}$ means the peak area of the reference substance, $\mathrm{mAu} ; m$ is the sample weight, $\mathrm{g}$; the volume of the sample $V_{\text {load }}$ is the sample volume loaded on the machine, $\mathrm{mL} ; V_{\text {removal }}$ is the sample volume removed.

\section{The Major Source of Measurement Uncertainty}

The method of Determination of Amino Acids in Foods according to $\mathrm{GB} / \mathrm{T}$ 5009.124-2003A [4], there are the following mainly sources of uncertainty: (1) the uncertainty introduced by sample weight; (2) the uncertainty introduced by sample volume; (3) sample process introduces uncertainty; (4) the uncertainty introduced by the sample 
Table 2. The content of threonine in different volume injection sample $(n=6)$.

\begin{tabular}{|c|c|c|c|c|}
\hline Sample Amount, m(g) & Peak area & Result R, (\%) & Mean, (\%) & RSD, (\%) \\
\hline 0.2083 & 469234 & 0.2968 & \multirow{6}{*}{0.2971} & \multirow{6}{*}{0.008656} \\
\hline 0.2056 & 461412 & 0.2958 & & \\
\hline 0.2053 & 457122 & 0.2933 & & \\
\hline 0.2028 & 463257 & 0.3009 & & \\
\hline 0.2015 & 456055 & 0.2982 & & \\
\hline 0.2084 & 471341 & 0.2979 & & \\
\hline
\end{tabular}

peak area; (5) the uncertainty introduced by sample measurement repeat; (6) the uncertainty introduced by the non-linear of standard curve.

\section{Evaluation of Measurement Uncertainty}

The samples weighing introduced uncertainty $[\mathrm{u}(\mathrm{m})]$ : The balance calibration introduced uncertainty: the balance test showed analytical balance error was $0.1 \mathrm{mg}$, according to rectangular distribution $(k=\sqrt{3})$, uncertainty component introduced by the balance calibration:

$u(m)=\sqrt{2\left[(0.00005)^{2}+(0.00005)^{2}\right]}=0.0001 g$

Weighing variability introduced uncertainty: according to Uncertainty Evaluation Guide in chemical analysis [5], the analytical balance variability is about $0.5 \times$ the final significant figure, and the final significant figure of the analysis balance in our laboratory was $0.1 \mathrm{mg}$. So, weighing variability introduced the uncertainty components:

$u_{2}(m)=0.5 \times 0.1 m g=0.00005 g$

Weighing by the difference method should calculated uncertainty twice, so the uncertainty introduced by the weighing scales:

$u(m)=\sqrt{2\left[(0.00005)^{2}+(0.00005)^{2}\right]}=0.0001 g$

The sample weighted $m=0.2083 \mathrm{~g}$, the relative standard uncertainty introduced by weighing:

$u_{\text {rel }}(m)=0.0001 g / 0.2083 g=0.000480$

\section{The Final Volume of Samples Introduced Uncertainty [u(V)]}

$50 \mathrm{~mL}$ volumetric flask bring uncertainty: the uncertainty brought by the volume container includes the following four sources:

Uncertainty introduced by the calibration error: $50 \mathrm{~mL} A$ grade volumetric flask error allowed $\pm 0.05 \mathrm{~mL}$ [1] rectangular distribution $(k=\sqrt{3}), 50 \mathrm{~mL}$ volumetric flask calibration introduced uncertainty:
$u_{1}\left(V_{\text {volume } 50}\right)=0.05 \mathrm{~mL} / \sqrt{3}=0.0288 \mathrm{~m} L$

Repeatability: filled 10 times to $50 \mathrm{~mL}$ volumetric flask in one experiments, the standard deviation $0.02 \mathrm{~mL}$ can be directly as uncertainty, namely: $\mathrm{u}_{2}\left(\mathrm{~V}_{50}\right)=0.02 \mathrm{~mL}$.

Uncertainty introduced by the temperature: the temperature range is $\pm 5^{\circ} \mathrm{C}$, in the manual, water expansion coefficient is $2.1 \times 10^{-4} \mathrm{~mL}^{\circ} \mathrm{C}^{-1}$, then $50 \mathrm{~mL}$ volumetric flask volume change were:

$\Delta V_{\text {volume } 50}=50 \times 2.1 \times 10^{-4} \times 5=0.0525 \mathrm{~mL}$

The confidence level of 0.95 , contains the factor $K=$ 1.96 , the uncertainty introduced by the temperature change:

$\mathrm{u}_{3}\left(V_{\text {volume } 50}\right)=0.0525 \mathrm{~mL} / 1.96=0.0267 \mathrm{~mL}$

Uncertainty components caused by reading: relative standard uncertainty introduced from $50 \mathrm{~mL}$ volumetric flask:

$\mathrm{u}_{4}\left(V_{\text {volume } 50}\right)=0.01 \times 50 \mathrm{~mL} / \sqrt{6}=0.204 m L$

The relative standard uncertainty brought by $50 \mathrm{ml}$ volumetric fask:

$u_{\text {rel }}\left(V_{\text {volume } 50}\right)=\sqrt{0.0288^{2}+0.02^{2}+0.0267^{2}+0.204^{2}} / 50 \mathrm{~mL}=0.00156$

\section{Simple Processing Introduced Uncertainty [u(rep)]}

Repeatable measurement introduced uncertainty: the threonine content repeatable measurement results are shown in Table 3, the standard deviation obtained by Bessel formula:

$S_{x}=\sqrt{\frac{\sum_{n=1}^{i}\left(x_{i}-\bar{x}\right)^{2}}{n-1}}=0.000386 \%$

Repeatability uncertainty:

$u_{\text {rel }}($ rep $)=u_{(\text {rep })} / \bar{R}=\frac{0.000157 \%}{0.2971 \%}=0.000528$

$u_{(r e p)}=S_{x} / \sqrt{n}=0.000386 / \sqrt{6}=0.000157 \%$ 
Table 3. Peak area of threonine

\begin{tabular}{|c|c|c|c|}
\hline Sample Injected Order & Peak Area & Mean & RSD\% \\
\hline 1 & 469234 & \multirow{6}{*}{463070.1} & \multirow{6}{*}{0.01344} \\
\hline 2 & 461412 & & \\
\hline 3 & 457122 & & \\
\hline 4 & 463257 & & \\
\hline 5 & 456055 & & \\
\hline 6 & 471341 & & \\
\hline
\end{tabular}

Sample Peak Area Measurement Introduced Uncertainty [u(AS)]

\section{Generated Uncertainty of Peak Area by Repeated Measurements}

Because there is only 6 data in the Table 2, so use range method for evaluation according to Errors Analysis and Measurement Uncertainty Evaluation [6], in which $n=6, C$ $=2.53$.

$$
\mathrm{u}_{A}=\frac{R_{\text {range }}}{C_{\text {difference coefficient }}}
$$

Threonine: $u_{r e l}=\frac{u_{A}}{A}=\frac{6041.897}{463070.1}=0.0103$

\section{Instrumental Data Processing System Introduced Uncertainty}

According to instrument manual and the general performance of integrator, so far, the maximum error of peak area convolution procedure by the liquid chromatography is $0.2 \%$ to $1 \%$, then the peak area relative uncertainty components: $u_{A}=\frac{0.01}{\sqrt{3}}=0.00577$

Liquid chromatography used micro-injector for measurement, the injection uncertainty was $1 \%$, then the relative uncertainty components: ${ }_{\text {injection }}=\frac{0.01}{\sqrt{3}}=0.00577$

The uncertainty introduced by data-processing system:

$u_{\text {process }}=\sqrt{u_{A}^{2}+u_{\text {load }}^{2}}=0.0082$

So we can get the evaluation of the uncertainty introduced by sample peak area measurement: $u_{\text {rel }}\left(A_{S}\right)=\sqrt{u_{\text {process }}^{2}+u_{\text {rel }^{2}}}$

Threonine:

$u_{r e l}\left(A_{S}\right)=\sqrt{0.0103^{2}+0.0082^{2}}$
$=0.0131 \% ; u_{r e l}\left(A_{S}\right)=u_{(r e p)} / \bar{R}=\frac{0.0131 \%}{0.2971 \%}=0.0440$

The nonlinear standard curve introduced uncertainty [u(line)]: The preparation concentration $0,0.1,0.2,0.3,0.4$, $0.6 \mathrm{~mL}$ five threonine standard solution, measured twice for each concentration. According to the measurement data, using the least squares method to prepare standard working curve equation [6-8]: $A=9130 \mathrm{c}-0.002857$, correlation coefficient $r=1$. The standard deviation of the standard curve equation was calculated, i.e. residual standard deviation. The peak area measured values by instruments were calculated according to the linear equation (in Table 4).

Standard curve residual standard deviation

$S_{R}=\sqrt{\frac{\sum_{j=1}^{n}\left[A_{0 j}-\left(a+b C_{o j}\right)\right]^{2}}{n-2}}=37.562 \mathrm{mg} / \mathrm{L}$

The uncertainty introduced by standard curve fitting:

$u_{\text {(line) }}=\frac{S_{R}}{b} \sqrt{\frac{1}{p}+\frac{1}{n}+\frac{\left(\bar{C}-\bar{C}_{0}\right)^{2}}{\sum_{j=1}^{n}\left(C_{0 j}-\bar{C}_{0}\right)^{2}}}=\frac{37.562}{9130}$
$\sqrt{\frac{1}{6}+\frac{1}{12}+\frac{(50.7160-26.4)^{2}}{2286.9}}=0.00209 \mathrm{mg} / \mathrm{L}$

where $S_{R}$ : Residual standard deviation of standard curve (residual standard deviation); $b$ : Slope; $p$ : Repeatable times for the measurement of samples; $n$ : The points of standard curve; $\bar{C}$ : The mean of the sample concentration; $\bar{C}_{0}:$ The mean of the each points concentration on standard curve; $C_{0 j}$. The concentration of each standard solution.

So the uncertainty introduce by standard curve:

$u_{\text {rel }}($ line $)=\frac{u_{(\text {line })}}{\bar{C}}=\frac{0.00209 m g / L}{50.7160 m g / L}=0.0000412$

Composition Uncertainty, Expanded Uncertainty and their Results Expression

The above uncertainties are separated, so the composition relative uncertainty is: 
Table 4. The results of residual calculation for standard curve

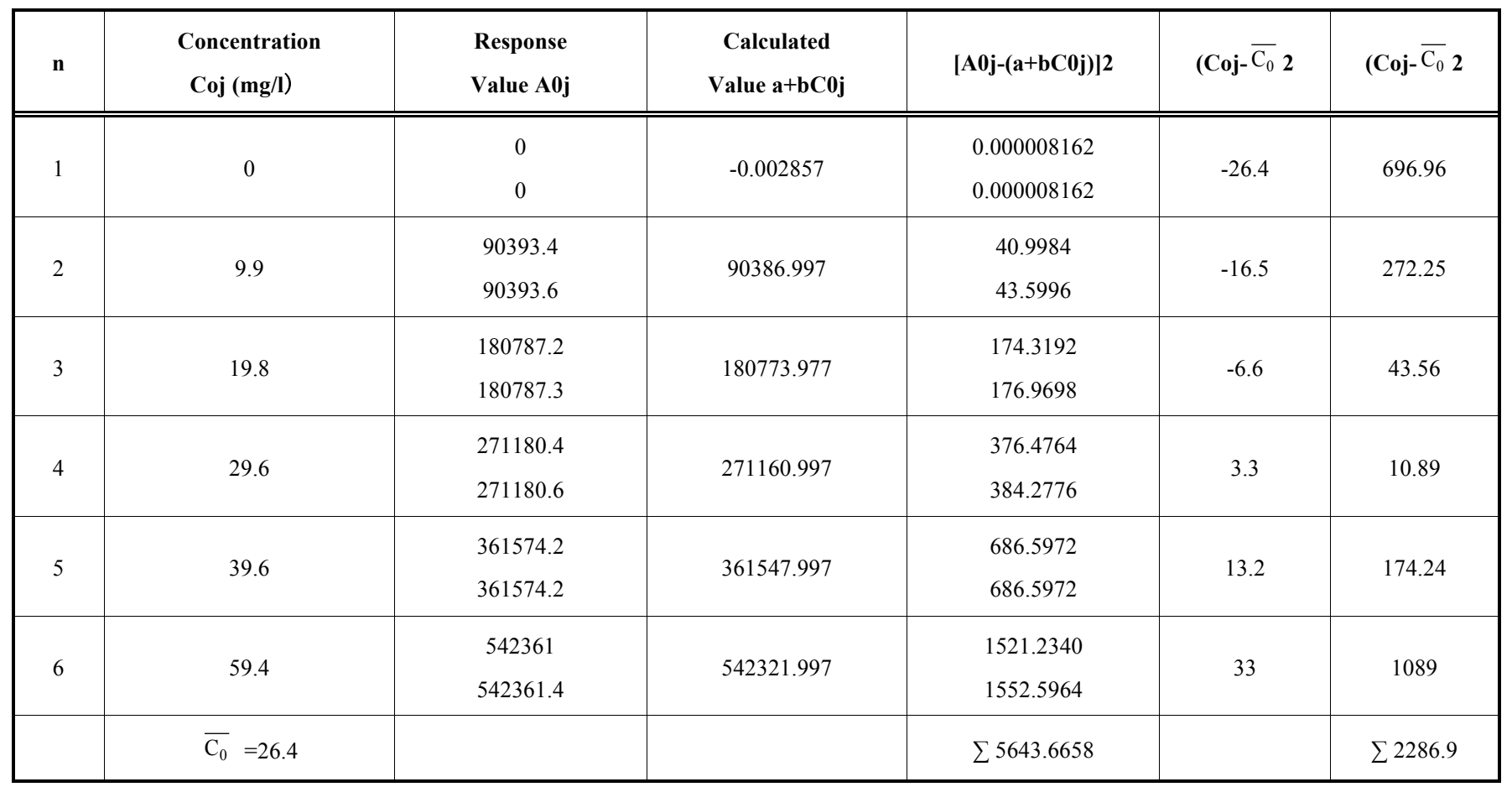

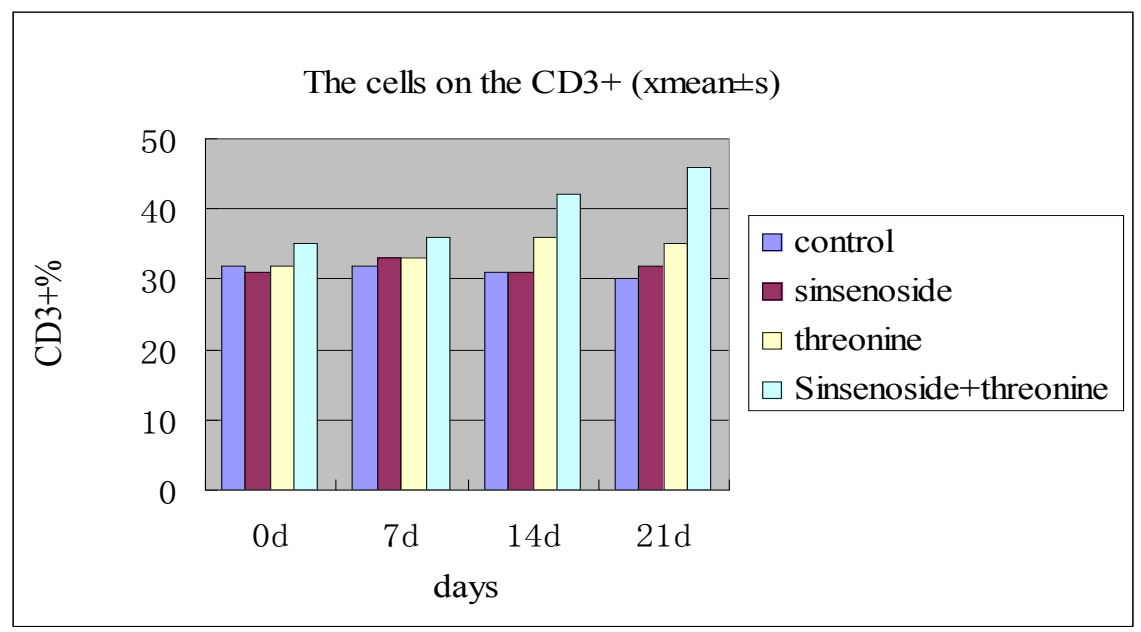

Fig. (1). Variation of $\mathrm{CD} 3+\mathrm{T}$ lymphocytes in spleen of mice after oral administration.

$$
\begin{aligned}
& \mathrm{u}_{\text {rel }}(R)=\sqrt{\begin{array}{l}
{\left[u_{r e l}(m)\right]^{2}+\left[u_{r e l}\left(V_{\text {volume } 50}\right)\right]^{2}} \\
+\left[u_{r e l}(r e p)\right]^{2}+\left[u_{r e l}(A s)\right]^{2}+\left[u_{r e l}(\text { line })\right]^{2}
\end{array}}
\end{aligned}
$$

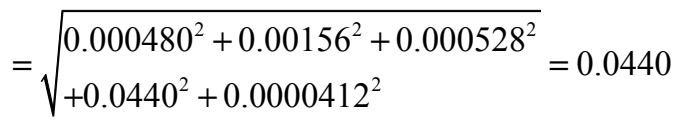

Composition uncertainty:

$$
u(R)=u_{r e l}(R) \times R=0.0440 \times 0.2971 \%=0.0130 \%
$$

in which, inclusion factor $k=2$; so the expended uncertainty:
$U=k u(R)=2 \times 0.0130 \%=0.0260 \%$

Finally, the content of threonine expressed as following:

$$
R=(0.2971 \pm 0.0260) \%, k=2
$$

\section{The Results of FACS}

CD4+T, CD8+T, CD19+ cell subgroups were detected by FACS, and analyzed DBS (Figs. 1-3).

After oral administration, the three test groups compared to the control group, the increase of CD3+T, CD4+/CD8+, and $\mathrm{CD} 19+$ is significant $(\mathrm{P}<0.01)$. The diversify of $\mathrm{CD} 3+\mathrm{T}, \mathrm{CD} 4+/ \mathrm{CD} 8+$, and $\mathrm{CD} 19+$ between groups 


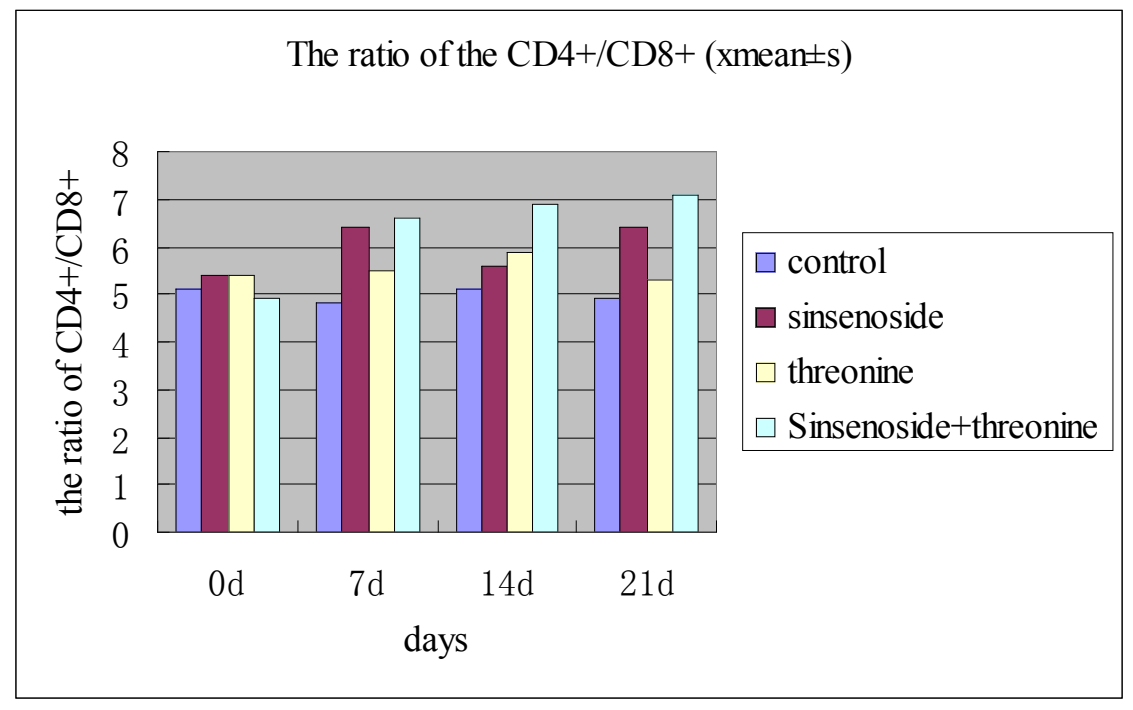

Fig. (2). Variation of $\mathrm{C} \mathrm{CD} 4^{+} / \mathrm{CD}^{+}$of lymphocytes in spleen of mice after oral administration.

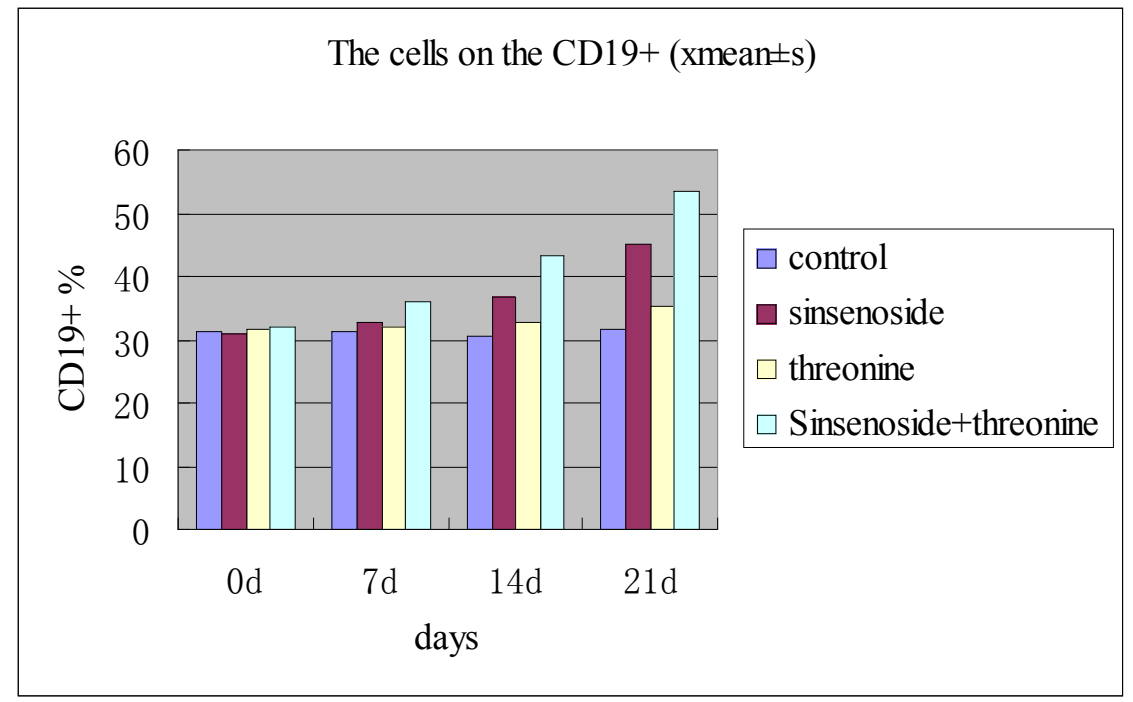

Fig. (3). Variation of CD19+T lymphocytes in spleen of mice after oral administration.

sinsenoside and threonine changed little ( $\mathrm{P}>0.05)$. Compared to control, sinsenoside and threonine group, the sinsenoside + threonine group, all tests change significantly $(\mathrm{P}<0.01)$. So the threonine can improve the immunity, also this activity of threonine threonine in ginseng has synergism with ginsenoside.

\section{CONCLUSION}

From the whole evaluating process of the uncertainty, when threonine in Ginseng was determined by amino acids assay, whose uncertainty comes mainly from the sample peak area. So the uncertainty introduced by the sample peak area is the largest component. So for the determination of threonine in Ginseng, the control of the instrument sensitivity could reduce the uncertainty components. To reduce this component is the efficient way to reduce the measurement uncertainty. Also the threonine play an important role on the enhancement of immunity, and this activity of threonine threonine in ginseng has synergism with ginsenoside. This study provides an effective analysis approaches for the identification of Ginseng, which is an important contribution for the application of Ginseng in Chinese Medicine.

\section{CONFLICT OF INTEREST}

The authors confirm that this article content has no conflict of interest.

\section{ACKNOWLEDGEMENTS}

This study was funded by the National Natural Science Funds of China (grant no. ISIS584763SN:2810171 and 81101899). And also was sponsored by Qing Lan Project: 53041305. 


\section{REFERENCES}

[1] Du Shuli, Zhangzhiqing, Xie Junyan, et al. JJG 196-2006 People's Republic of China National Metrological Verification regulation of working glass container, China Metrology Press, Beijing, China, 2006; 2-8.

[2] Ding Jingan, Huang Jian, Li Yong, et al. JJG 1036-2008 People's Republic of China National Metrological Verification regulation for Electronic balance, China Metrology Press, Beijing, China, 2008; $1-8$.

[3] Zhao Min, Wu Fangdi, He Yajuan. JJG 705-2002 People's Republic of China National Metrological Verification regulation of liquid chromatographs, China Metrology Press, Beijing, China, 2002; $1-15$.

[4] Jia Jianbin, Zhao Xihe. GB/T 5009.124-2003 Determination of Amino Acids in Foods, China Standard Publishing House, Beijing, China, 2003; 115-119.

[5] Wei Hao, Qiao D. Guidance on Evaluating the Uncertainty in Chemical Analysis. China Metrology Press, Beijing, China, 2002; 100-129.

[6] Sha Dingguo. Errors Analysis and Measurement Uncertainty Evaluation, China Metrology Publishing House, Beijing, China, 2003; 174-181.

Received: October 11, 2014

Revised: March 30, 2015

Accepted: July 28, 2015

(C) Qin et al.; Licensee Bentham Open.

This is an open access article licensed under the terms of the Creative Commons Attribution Non-Commercial License (http://creativecommons.org/licenses/by-nc/3.0/) which permits unrestricted, non-commercial use, distribution and reproduction in any medium, provided the work is properly cited. 